\title{
Age estimation by pulp to tooth area ratio in canine teeth using cone-beam computed tomography
}

\author{
Fatemeh Salemi ${ }^{1}$, Maryam Farhadian ${ }^{2}$, Bahare Askari Sabzkouhi ${ }^{3}$, Samira Saati ${ }^{1}$ and Nika Nafisi ${ }^{1}$
}

\begin{abstract}
Background: This study aimed to estimate the chronological age of individuals according to the correlation of age with morphological variables of the maxillary canine teeth using cone-beam computed tomography (CBCT) based on Kvaal's method.

Method: This study was conducted on CBCT scans of 300 patients in Hamadan city, including 142 females and 158 males between 14 and 60 years of age. To measure the morphological variables, cross-sectional views of the maxillary right canine tooth were studied. The pulp to tooth area ratio (AR), the pulp to tooth length ratio $(P)$, the mesiodistal and the buccolingual pulp to tooth width ratio at the cementoenamel junction (CEJ) (A1, A2), the mesiodistal and buccolingual pulp to tooth width ratio at the mid-root (C1, C2), and the mesiodistal and buccolingual pulp to tooth width ratio at the midpoint between the CEJ and the mid-root (B1, B2) were measured on CBCT scans.
\end{abstract}

Results: A significant inverse correlation was noted between age and all measured variables. No significant difference was found in the mean variables between males and females. The correlation between the actual age and estimated age in the regression model was 0.88. The mean square error (MSE) of prediction was 5.89 years; also, the mean absolute error (MAE) was 4.46 years.

Conclusion: The fitted regression model suggested in this study can estimate the age of individuals with acceptable accuracy and mean absolute error of lower than 5 years.

Keywords: Forensic odontology, Age estimation, Secondary dentin deposition, Cone-beam computed tomography

\section{Background}

Different parts of the human body can be used for age estimation. However, in severe accidents, burns or buried bodies, many human parts lose their natural form and cannot be used for age estimation (Cameriere et al. 2007; Farhadian et al. 2019). Teeth remain for years after death and are suitable for human age estimation (Igbigbi and Nyirenda, 2006). Also, teeth are least affected by the surrounding environment (Mathew et al. 2013). In children, age estimation using teeth is relatively simple and is done based on the developmental stage of the teeth.

\footnotetext{
* Correspondence: m.farhadian@umsha.ac.ir;

maryam_farhadian80@yahoo.com

${ }^{2}$ Department of Biostatistics, School of Public Health and Research Center for Health Sciences, Hamadan University of Medical Sciences, Hamadan, Iran Full list of author information is available at the end of the article
}

But, age estimation in adults is a challenge in forensic medicine (Jain and Rai 2009).

The tooth is the hardest part of the human body and is composed of the enamel and dentin (Yang et al. 2006). Assessment of morphological changes requires tooth sectioning, which is impossible in living individuals. Thus, methods used for age estimation are mainly based on radiographic imaging (Yang et al., 2006). In 1995, Kvaal et al. invented a method for age estimation based on the deposition of secondary dentin by measuring the pulp dimensions. They concluded that pulp width is strongly correlated with aging (Kvaal et al. 1995).

Any tooth can be used for age estimation. Canine teeth often remain in the oral cavity until old ages. They have a lower risk of caries and have one root and pulp 
chamber. Thus, they are suitable for age estimation (Cameriere et al. 2007).

Both panoramic and periapical radiography can be used for measurement of pulp to tooth ratio. The shortcomings of these modalities include two-dimensional (2D) nature of images, image magnification, and image distortion (Paewinsky et al. 2005). Moreover, digital radiography allows only linear measurements of the mesiodistal width of the tooth and pulp (Paewinsky et al. 2005).

At present, three-dimensional (3D) computed tomography (CT) and cone-beam computed tomography (CBCT) scans provide valuable $3 \mathrm{D}$ information about teeth and allow more accurate measurement of tooth and pulp dimensions compared with 2D radiography (Maret et al. 2011). CT is the most ideal and accurate method of measurement of pulp to tooth ratio (Yang et al. 2006).

$\mathrm{CBCT}$ as a new imaging modality is more commonly used in forensic odontology than the conventional CT due to higher resolution and lower radiation exposure. In addition, $\mathrm{CBCT}$ enables measuring the dimensions of the tooth and pulp in both mesiodistal and buccolingual dimensions. Also, it enables determining the exact volume of the teeth and pulp, which is not possible by 2D radiography (Maret et al. 2011; Salemi et al. 2018). Considering the lower patient radiation dose and higher image resolution of $\mathrm{CBCT}$ compared with $\mathrm{CT}$, recent studies on age estimation have mainly used CBCT images for this purpose (Maret et al. 2011). Considering the small number of studies on the application of CBCT for age estimation, we aimed to estimate age according to CBCT images of canine teeth by calculating the pulp to tooth ratio.

\section{Materials and methods}

In this study, CBCT scans of patients were retrieved from the archives of two private clinics. CBCT scans had been requested for implant therapy or other medical conditions not related to this study.

The study was approved by the Ethics Committee of Hamadan University of Medical Sciences (IR.UMSHA.REC .9209103130). CBCT scans of 300 patients (142 females and 158 males) with a mean age of $36 \pm$ 12.56 years were used in this study. The CBCT scans had been taken with Cranex 3D CBCT system (Soredex, Helsinki, Finland) with the exposure settings of $90 \mathrm{kVp}$, $8 \mathrm{~mA}$, and $6.12 \mathrm{~s}$ time and had been saved in OnDemand software (Cybermed, Seoul, Korea). The inclusion criteria were patient age between 14 and 60 years, fully erupted maxillary canine teeth, completely formed root of maxillary canine teeth and absence of root filling, extensive restorations, developmental defects, or anomalies in maxillary canine teeth.
To control for the confounders, patients with a history of systemic diseases were excluded. Only the maxillary right canine tooth was evaluated. The CBCT scans with low resolution were excluded as well.

To measure the pulp to tooth ratio, cross-sectional images of the teeth were reconstructed with $1 \mathrm{~mm}$ slice thickness and $1 \mathrm{~mm}$ interval. The section passing right through the center of the canine tooth was chosen. For measurement of the tooth and pulp surface areas, the area measurement tool of On-Demand software was used. Twenty points on the tooth periphery and 10 points on the pulp borders were identified and connected to calculate the pulp and tooth surface areas in square millimeters $\left(\mathrm{mm}^{2}\right)$. Tooth length, pulp length, and buccolingual width of tooth and pulp at three levels were measured by the length measurement tool of OnDemand software on cross-sectional slices. Moreover, the mesiodistal width of tooth and pulp at three levels was measured on reconstructed panoramic images using the software. The ratio of measurements was abbreviated as follows:

AR, tooth to pulp area ratio (Fig. 1)

$P$, tooth to pulp length ratio (Fig. 2)

A1, buccolingual root to pulp width ratio at the cementoenamel junction (CEJ)

A2, mesiodistal tooth to pulp width ratio at the CEJ

$\mathrm{C} 1$, buccolingual root to pulp width ratio at the midroot

$\mathrm{C} 2$, mesiodistal root to pulp width ratio at the midroot (Figs. 3 and 4)

B1, mesiodistal pulp to tooth width ratio at the middle of $\mathrm{A}$ and $\mathrm{C}$

B2, buccolingual pulp to tooth width ratio at the middle of $\mathrm{A}$ and $\mathrm{C}$

Two oral and maxillofacial radiologists with 8 years of clinical experience performed the measurements. Each observer made each measurement twice with a 2-week interval. Age and gender of patients were collected from their medical files. The intra-class correlation coefficient was calculated to assess the inter-observer (reproducibility that was determined using the data of the two independent examiners) and intra-observer (repeatability that was evaluated by asking both examiners to assess $50 \%$ of the CBCT images at two separate sessions) agreements.

Data were analyzed using SPSS version 19. To analyze the data by the regression model, the data set was randomly divided into training ( $70 \%$ of the data) and test (30\% of the data) groups. For calculation of prediction indices, the regression model was applied to the training set to fit the parameters of regression model, and then the test set was used to calculate the evaluation measures. For age estimation using the measured variables, the multiple linear regression model was used. To 


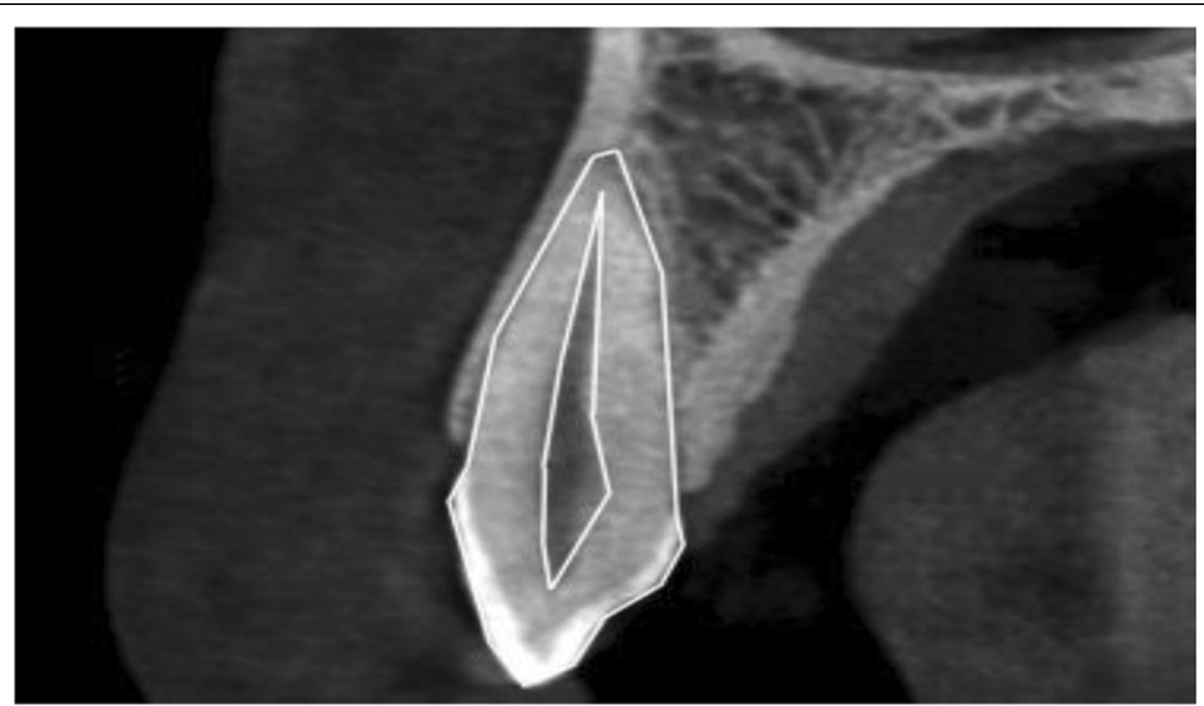

Fig. 1 Pulp to tooth area ratio

calculate the correlation of actual and estimated age, Pearson's correlation coefficient was used. The intraclass correlation coefficient was calculated to assess the inter- and the intra-observer agreements.

\section{Results}

The intra- and inter-observer agreements were found to be very high. Also, both observers had high reliability (intraclass correlation coefficient $=0.94$ ).

Of 300 individuals, 142 were females and 158 were males. The mean age of participants was 36 years. Table 1 shows the Pearson's correlation coefficient for the correlation between age and the measured variables. As shown, the correlation coefficient for the correlation of age and the measured variables was negative. This indicates that by an increase in age, the magnitude of these variables decreased. The strongest inverse correlation was noted between age and AR while the weakest inverse correlation was noted between age and $P$.

The $t$ test was used to compare the mean variables between males and females. Table 2 presents the results. As shown in Table 2, no significant difference was found between males and females regarding the measured variables $(P>0.05)$. Since the values of all variables were the same in males and females, and also the correlation pattern between these variables and age was the same in males and females, the multiple linear regression was used for age estimation according to the measured variables.

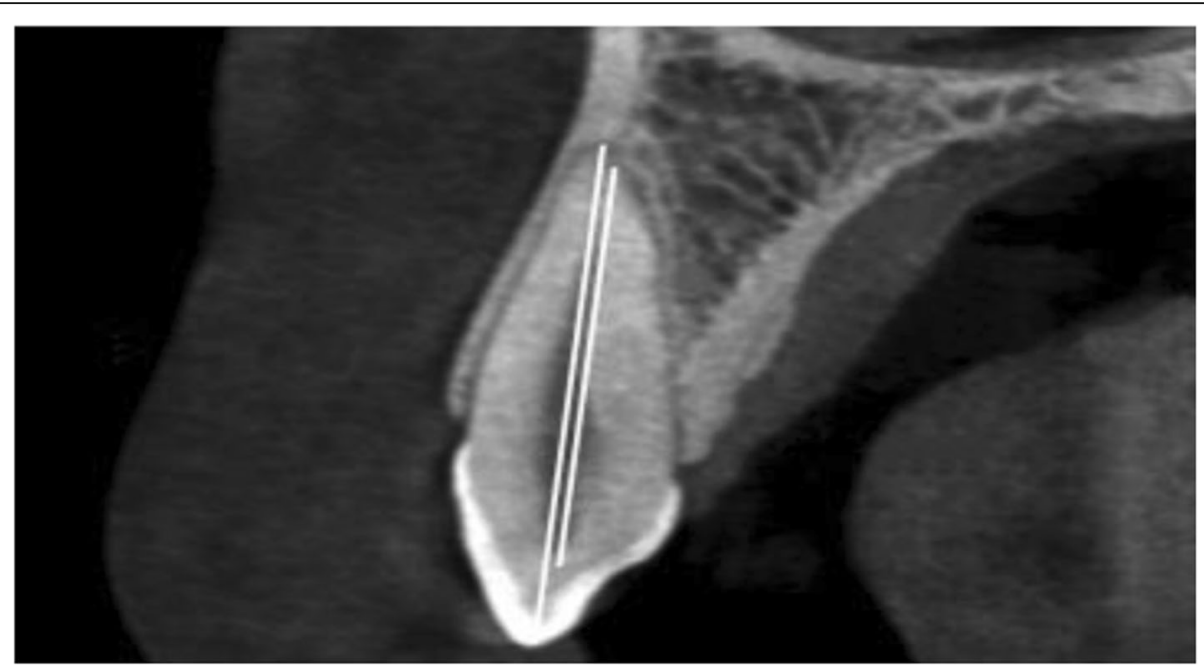

Fig. 2 Pulp to tooth length ratio 


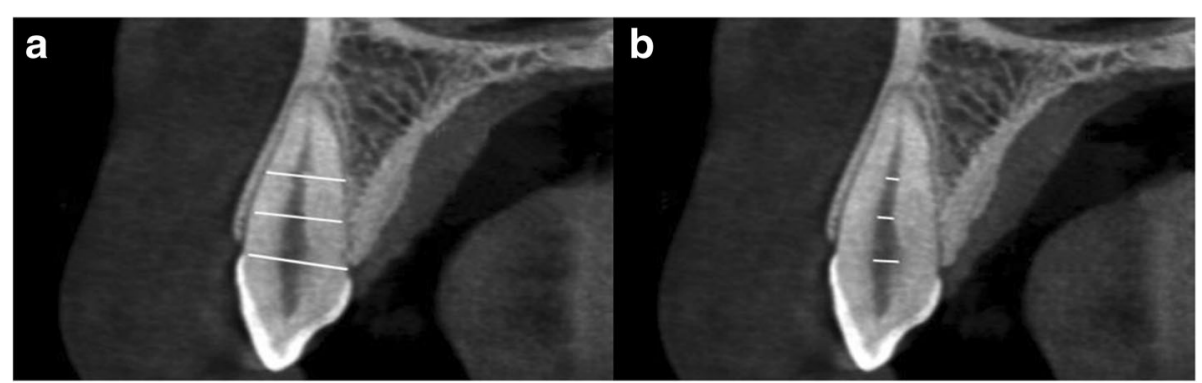

Fig. 3 a, b Pulp to root width ratio at cementoenamel junction level and mid-root level and midpoint between the cementoenamel junction and the mid-root in cross section image

To find an ideal regression model for age estimation, two methods were used. First, all the respective variables were entered into the regression model. Next, the respective variables were entered into the regression model using the forward selection method. Table 3 shows the results of fitness of the regression model with all variables and also with the use of the forward method for all data as well as indices for the prediction performance of the model.

The indices to assess the performance of the regression model in this study were the correlation coefficient between the actual age and estimated age, the coefficient of determination indicating that what percentage of the change in age (dependent variable) is determined by the independent variables, morphological variables of maxillary canine tooth, the mean square of errors (MSE), and the mean absolute error (MAE), defined as follows:

$$
\begin{aligned}
& \text { MSE }=\text { Mean square error }=\sqrt{\frac{\sum(\text { Age }- \text { Predicted } \text { age })^{2}}{n}} \\
& \text { MAE }=\text { Mean } \text { absolute error }=\frac{\sum \mid \text { Age-Predicted } \text { age } \mid}{n}
\end{aligned}
$$

As shown in Table 3, the fitted regression model using the forward method had a better performance in age estimation. Thus, the following regression model was chosen as the best-fitted model for age estimation:

Age $=57.88-380.90 \mathrm{AR}+72.68 \mathrm{~A} 2-60.17 \mathrm{~B} 1+33.15 \mathrm{P}$ $+30.69 \mathrm{~A} 1$

Based on the results, only P, B1, A1, A2, and AR were significantly correlated with age. In the selected model, indices for assessment of the fitted regression model based on the test data indicated that the fitted regression model was suitable. The correlation between the actual age and estimated age in the regression model was significant $(0.88)$. The root of the MSE was 5.89 years, the MAE was 4.46 years, and the coefficient of determination (R2) was 0.77 .

Paired $t$ test was used to compare the actual and estimated age by the forward regression model with significant variables $(n=300)$. As shown in Table 4 , the difference between the actual and estimated mean age for 30-40-year-olds was not significant $(P>0.05)$ while this difference was significant for other age groups $(P<0.05)$. For an individual younger than 40 years of age, the predicted age was higher than the actual age (overestimation). But for the age group above 40 years of age, the predicted age was lower than the actual age (underestimation).

\section{Discussion}

Maxillary canine teeth were used in this study because they are single-rooted and have a single canal as well as

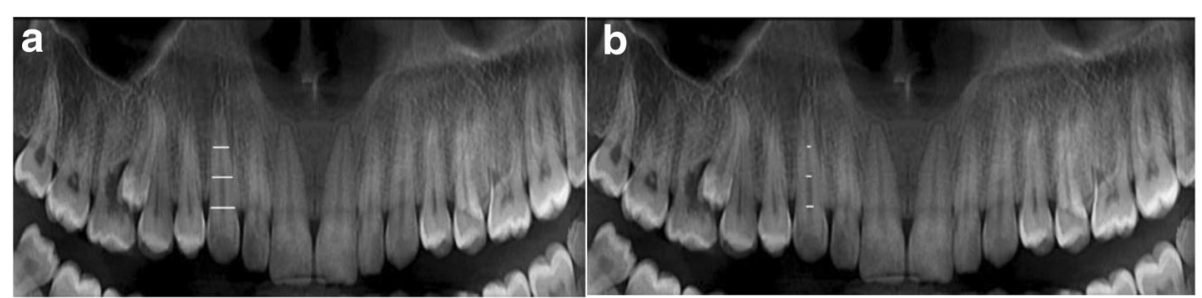

Fig. 4 a, b Pulp/root width ratio at cementoenamel junction level and mid-root level and midpoint between the cementoenamel junction and the mid-root in panoramic-like image 
Table 1 Pearson's correlation coefficient between age and the measured variables

\begin{tabular}{|c|c|c|c|c|c|c|c|c|}
\hline Variable & B2 & B1 & $\mathrm{C} 2$ & $\mathrm{C} 1$ & $\mathrm{~A} 2$ & A1 & $P$ & $A R$ \\
\hline Correlation coefficient $(n=300)$ & -0.579 & -0.428 & -0.246 & -0.401 & -0.600 & -0.406 & -0.160 & -0.779 \\
\hline$P$ value & 0.000 & 0.000 & 0.000 & 0.000 & 0.000 & 0.000 & 0.000 & 0.000 \\
\hline Correlation coefficient for female $(n=142)$ & -0.612 & -0.429 & -0.225 & -0.390 & -0.582 & -0.430 & -0.140 & -0.794 \\
\hline$P$ value & 0.000 & 0.000 & 0.000 & 0.000 & 0.000 & 0.000 & 0.000 & 0.000 \\
\hline Correlation coefficient for male $(n=142)$ & -0.576 & -0.434 & -0.266 & -0.415 & -0.614 & -0.380 & -0.179 & -0.767 \\
\hline$P$ value & 0.000 & 0.000 & 0.000 & 0.000 & 0.000 & 0.000 & 0.000 & 0.000 \\
\hline
\end{tabular}

a well-defined pulp chamber. Moreover, most individuals retain their maxillary canines until old ages and these teeth are less worn over time. Indira et al. (2015) chose the maxillary left central incisors in their study. Cameriere et al. (2012) chose the mandibular premolars. Afify et al. evaluated mandibular canines and premolars (Afify et al., 2014).

The Kvaal's method is the gold standard of age estimation using pulp to tooth ratio, which was used as the basis in our study. This method has been used in other studies as well (Kvaal et al. 1995; Cameriere et al. 2007; Babshet et al. 2010). Assessment of the pulp to tooth area ratio, in particular, is an indirect indicator of secondary dentin deposition. In the current study, the Pearson's correlation coefficient indicated an inverse correlation between age and all morphological variables. This finding indicated that the mean of different variables decreased by aging. These results were in agreement with those of Cameriere et al. (2007). Kvaal et al. (1995) also showed that the correlation coefficient for the correlation between age and most of the measured ratios was negative. Jeon et al. (2015) reported that the ratio of height from the pulp chamber floor to the furcation area to the crown length was the only variable that had a positive correlation with age. These results indicate that the deposition of secondary dentin is a continuous, age-dependent phenomenon. By an increase in age and deposition of secondary dentin, the size of the pulp chamber decreases.

In the current study, the strongest negative correlation was noted between age and AR while the weakest negative correlation was noted between age and $P$. Juneja et al. (2014) reported that AR had the strongest negative correlation with age. Moreover, horizontal ratios compared with longitudinal ratios had a stronger correlation with age and it can be stated that they are more accurate indices for age estimation. These results were in line with those of Kvaal et al., Indira et al., Bosmans et al., and Cameriere et al. (Kvaal et al., 1995; Indira et al., 2015; Bosmans et al., 2005; Cameriere et al., 2009). It seems that longitudinal ratios cannot serve as acceptable indices for age estimation due to the confounding effect of factors such as attrition, type of occlusion, or behavioral habits. Cameriere et al. reported that the pulp to tooth $\mathrm{AR}$ in mandibular premolars was a suitable variable for age estimation with acceptable accuracy, and this ratio decreased with aging, which was in line with the current findings (Cameriere et al. 2012).

In our study, no significant difference was noted between males and females in the mean variables. Saxena found no significant difference in morphological variables between males and females (Saxena 2011). Cameriere et al., Babshet et al., Afify et al., and Mathew et al. found no significant difference between males and

Table 2 Comparison of the mean variables in males and females using $t$ test

\begin{tabular}{|c|c|c|c|c|c|c|c|c|c|c|}
\hline \multirow[b]{2}{*}{ Variable } & \multicolumn{3}{|c|}{ Total $(n=300)$} & \multicolumn{3}{|c|}{ Female $(n=142)$} & \multicolumn{3}{|c|}{ Male $(n=158)$} & \multirow{2}{*}{$\begin{array}{l}t \text { test } \\
P \text { value }\end{array}$} \\
\hline & Min & Max & $\mathrm{SD} \pm$ mean & Min & Max & $\mathrm{SD} \pm$ mean & Min & Max & $\mathrm{SD} \pm$ mean & \\
\hline Age & 14 & 60 & $36.00 \pm 12.56$ & 14 & 60 & $35.06 \pm 12.75$ & 14 & 60 & $36.83 \pm 12.37$ & 0.226 \\
\hline$A R$ & 0.08 & 0.25 & $0.162 \pm 0.035$ & 0.08 & 0.25 & $0.164 \pm 0.034$ & 0.09 & 0.25 & $0.161 \pm 0.036$ & 0.387 \\
\hline$P$ & 0.56 & 0.88 & $0.773 \pm 0.055$ & 0.56 & 0.86 & $0.773 \pm 0.055$ & 0.57 & 0.88 & $0.773 \pm 0.056$ & 0.937 \\
\hline $\mathrm{A} 1$ & 0.08 & 0.31 & $0.197 \pm 0.044$ & 0.11 & 0.31 & $0.199 \pm 0.044$ & 0.08 & 0.31 & $0.194 \pm 0.045$ & 0.256 \\
\hline $\mathrm{A} 2$ & 0.14 & 0.40 & $0.046 \pm 0.274$ & 0.15 & 0.40 & $0.046 \pm 0.274$ & 0.14 & 0.39 & $0.046 \pm 0.274$ & 0.342 \\
\hline $\mathrm{C} 1$ & 0.06 & 0.30 & $0.045 \pm 0.168$ & 0.06 & 0.28 & $0.044 \pm 0.167$ & 0.08 & 0.30 & $0.045 \pm 0.168$ & 0.768 \\
\hline $\mathrm{C} 2$ & 0.08 & 0.41 & $0.050 \pm 0.156$ & 0.10 & 0.41 & $0.055 \pm 0.158$ & 0.08 & 0.38 & $0.046 \pm 0.154$ & 0.489 \\
\hline B1 & 0.05 & 0.32 & $0.045 \pm 0.195$ & 0.07 & 0.32 & $0.043 \pm 0.194$ & 0.05 & 0.30 & $0.047 \pm 0.196$ & 0.604 \\
\hline B2 & 0.10 & 0.41 & $0.057 \pm 0.247$ & 0.10 & 0.40 & $0.050 \pm 0.246$ & 0.10 & 0.41 & $0.063 \pm 0.247$ & 0.902 \\
\hline
\end{tabular}


Table 3 Results of regression model for all data

\begin{tabular}{|c|c|c|c|c|c|c|c|c|}
\hline & \multirow[t]{2}{*}{ Variable } & \multicolumn{2}{|c|}{ Unstandardized coefficients } & \multirow{2}{*}{$\begin{array}{l}P \\
\text { value }\end{array}$} & \multicolumn{4}{|c|}{ Model evaluation criteria } \\
\hline & & $B$ & SE & & $R$ & $R^{2}$ & MAE & RMSE \\
\hline \multirow[t]{9}{*}{ Regression with all variable $(n=300)$} & Constant & 60.31 & 6.73 & 0.000 & 0.81 & 0.66 & 5.20 & 7.37 \\
\hline & $A R$ & -311.75 & 23.79 & 0.000 & & & & \\
\hline & $P$ & 30.49 & 9.52 & 0.002 & & & & \\
\hline & $\mathrm{A} 1$ & 25.14 & 15.87 & 0.114 & & & & \\
\hline & $\mathrm{A} 2$ & 53.70 & 19.23 & 0.006 & & & & \\
\hline & $\mathrm{C} 1$ & -11.26 & 15.49 & 0.468 & & & & \\
\hline & $\mathrm{C} 2$ & 4.79 & 11.07 & 0.665 & & & & \\
\hline & B1 & -45.26 & 15.97 & 0.005 & & & & \\
\hline & B2 & -28.50 & 11.49 & 0.017 & & & & \\
\hline \multirow[t]{6}{*}{ Regression with forward variable selection $(n=300)$} & Constant & 57.88 & 5.19 & 0.000 & 0.88 & 0.77 & 4.46 & 5.89 \\
\hline & AR & -380.90 & 19.21 & 0.000 & & & & \\
\hline & $\mathrm{A} 2$ & 72.68 & 15.04 & 0.000 & & & & \\
\hline & B1 & -60.17 & 11.04 & 0.000 & & & & \\
\hline & $P$ & 33.15 & 7.54 & 0.000 & & & & \\
\hline & A1 & 30.69 & 11.83 & 0.000 & & & & \\
\hline
\end{tabular}

females either (Cameriere et al. 2012; Babshet et al. 2010; Afify et al. 2014; Mathew et al., 2013). Their findings were in agreement with ours. Yayun et al. found a significant difference between males and females in a Chinese population and reported that in males, the canal/root diameter ratio had a greater correlation with the estimated age compared with females (Wu et al., 2016). Zaher et al. found a significant difference between males and females as well (Zaher et al. 2011). Angles et al. showed a moderate correlation between the pulp to tooth volume ratio and estimated age in females while this correlation was weak in males; however, this difference did not reach statistical significance (De Angelis et al., 2015). Star et al. showed that the correlation between pulp to tooth volume ratio and age in females was stronger than that in males, but it was not significant (Star et al. 2011). Thus, there would be no reason to justify using gender along with ratio and type of tooth for age estimation. Data analysis by Azrak et al. revealed that using the obtained models, age estimation in females was slightly more accurate than in males (Azrak et al. 2007). Kvaal et al. reported that gender was a predictive factor only for the mandibular lateral incisors, and since this value was negative, they concluded that pulpal changes in males occur faster than in females (Kvaal et al. 1995). According to the aforementioned studies, taking into account the race and type of tooth, gender may be an influential factor in age estimation.

In the current study, the regression model obtained by using the forward method showed that only $P, \mathrm{~B} 1, \mathrm{~A} 1$, A2, and AR had a significant correlation with age. In a study by Saxena, of all the measured variables, only AR and $C$ had significant correlations with age (Saxena 2011). In the study by Cameriere et al., a significant correlation was noted between AR of mandibular premolars and age, and this ratio was considered as a valuable variable for age estimation with acceptable accuracy (Cameriere et al. 2012). Juneja et al. evaluated the maxillary canine teeth and showed that AR and $B$ parameters

Table 4 Comparison of the actual and estimated age by the regression model including significant variables $(n=300)$

\begin{tabular}{llllll}
\hline $\begin{array}{l}\text { Age } \\
\text { group } \\
\text { (year) }\end{array}$ & $N$ & $\begin{array}{l}\text { Observed age } \\
\text { Mean } \pm \text { SD }\end{array}$ & $\begin{array}{l}\text { Predicted age } \\
\text { Mean } \pm \text { SD }\end{array}$ & $\begin{array}{l}\text { Difference (predict-observed) } \\
\text { Mean } \pm \text { SD }\end{array}$ & $\begin{array}{l}P \\
\text { value }\end{array}$ \\
\hline Under 20 & 37 & $17.14 \pm 1.68$ & $20.58 \pm 6.57$ & $3.45 \pm 6.48$ & 0.003 \\
$20-30$ & 76 & $25.32 \pm 2.73$ & $27.47 \pm 5.71$ & $2.15 \pm 4.97$ & 0.000 \\
$30-40$ & 70 & $35.26 \pm 2.74$ & $35.65 \pm 5.42$ & $0.29 \pm 5.62$ & 0.569 \\
$40-50$ & 70 & $45.82 \pm 3.05$ & $44.62 \pm 3.87$ & $-1.21 \pm 4.58$ & 0.033 \\
$50-60$ & 47 & $54.21 \pm 2.71$ & $48.75 \pm 4.95$ & $-5.47 \pm 5.21$ & 0.000 \\
\hline
\end{tabular}


were more influential and were used in the regression model (Juneja et al., 2014).

Landa et al. reported the highest correlation for $B$ ratio in the first premolars of both males and females (Landa et al. 2009). All the abovementioned findings are in agreement with our results. However, we did further evaluations and measured the pulp width at three levels of $\mathrm{A}, \mathrm{B}$, and $\mathrm{C}$ from both the buccolingual and mesiodistal directions, which has not been performed in any previous study. Thus, our study enabled further assessment of changes in pulp chamber dimensions that occur by aging. All variables measured in buccolingual direction (A2, B2, and $\mathrm{C} 2$ ) and one of the variables measured in mesiodistal dimension (B1) showed a significant association with age. This indicates that secondary dentin deposition does not occur uniformly on all the pulp cavity walls and may even vary depending on the type of tooth. Jeon et al., in 2015, evaluated the longitudinal ratios in mandibular first molars and concluded that the pulp chamber/crown height ratio had a greater correlation with the estimated age (Jeon et al. 2015). Mathew et al., in their study in 2016, showed that the ratio of pulp chamber to root height in the mandibular first molars had a stronger negative correlation with age (Mathew et al., 2013).

In our study, the regression model included significant variables namely the root of the MSE of prediction of 5.89 years and the MAE of 4.46 years. Cameriere et al. reported the MAE to be 4.34 to 6.02 years (Cameriere et al., 2012). They indicated that the pulp to tooth ratio was a beneficial variable for age estimation with acceptable accuracy. Jagannathan et al. in India reported the MAE of 8.54 years, which was significantly lower than the error in the Belgian formula (Jagannathan et al. 2011). The MAE of the model in the study by Jeon et al. was found to be $6.07-6.58$ years. This value was 6.96 years in the study by Mathew et al. (Jeon et al. 2015; Mathew et al. 2013). The standard error of estimate was 3.0186 years in the study by Juneja et al., 0.6 years in the study by Saxena, 5.35 years in the study by Cameriere et al., 2.28-3.05 years in the study by Yang et al., 1.25.08 years in the study by Zaher et al., and $4.10-5.66$ years in the study by Afify et al. (Juneja et al., 2014; Saxena 2011; Cameriere et al. 2012; Yang et al., 2006; Zaher et al. 2011; Afify et al. 2014). These values indicate that population-specific formula should be employed for age estimation in different communities. Also, the obtained regression equation may vary depending on the geographical location, race, type of tooth, and the significant variables. Babshet et al. indicated that the Italian formula was not suitable for the Indian population (Babshet et al. 2010).

In our study, except for the age group of 30 to 40 years, a significant difference existed between the actual age and predicted age in other age groups. In the age groups of younger than 20 years, 20 to 30 years and 30 to 40 years, the mean estimated values were higher than the actual values. In fact, estimations made by the regression model for different age groups were averagely higher than the actual age. For the age groups of 40 to 50 years and 50 to 60 years, the mean of predicted values was lower than the actual values. The regression model suggested by Babshet et al. overestimated the values for adolescents and underestimated the values for the elderly (Babshet et al. 2010). It should be mentioned that although the difference between the actual and estimated age in many age groups was statistically significant, this difference in the worst situation was 5 years for the oldest age group. This finding was in line with that of studies by Cameriere et al., Bosmans et al., and Saxena et al. In the study by Juneja et al., no significant difference was found between the actual and estimated age, which was in line with the results of Singaraju et al. and Mathew et al., which was the same for the three age groups (Singaraju and Sharada, 2009; Mathew et al. 2013).

Most studies using $\mathrm{CBCT}$ for age estimation measured the pulp volume. However, the CBCT software we used did not allow for volumetric measurement; thus, we only measured the pulp surface area and the buccolingual and mesiodistal dimensions of the pulp.

Last but not least, it should be mentioned that age estimation by measurement of dental pulp dimensions has some limitations. This method cannot be used for multirooted teeth because accurate measurements in such teeth are very difficult. On the other hand, it should be noted that the results of a study on a specific population cannot be generalized to other communities. Therefore, similar studies should be performed on a larger sample size to assess the effect of influential factors other than age and gender.

\section{Conclusion}

According to the results of this study, it may be concluded that a linear correlation exists between the pulp to tooth area ratio and pulp to tooth width ratio at the CEJ, the mid-root and midpoint between the CEJ, and the mid-root in the maxillary right canine with chronological age in our study population. Using the regression model obtained in this study, age can be estimated with a mean error of lower than 5 years. Although the fitted regression model in this study can estimate the age of individuals with an acceptable error and the MAE of less than 5 years, it is necessary to employ more accurate prediction methods than the conventional regression models for more accurate age estimation. 


\section{Abbreviations}

CBCT: Cone-beam computed tomography

\section{Acknowledgements}

This work is a part of the dentistry thesis was supported by Dental Research Center, Vice Chancellor of Research, Hamadan University of Medical Sciences.

\section{Authors' contributions}

FS contributed to the conception, data acquisition, design, and interpretation and critically revised the manuscript. MF contributed to the conception, design, data analysis, interpretation and drafted the manuscript. SS contributed to the conception and critically revised the manuscript. BA contributed to critically revise the manuscript. NN contributed to data acquisition and critically revised the manuscript. All authors read and approved the final manuscript.

\section{Funding}

The research had no fund from any agency.

\section{Availability of data and materials}

Please contact the authors for data requests.

\section{Ethics approval and consent to participate}

In this study, archived CBCT scans from 300 patients referred to two private jaw radiology centers of Hamadan were studied. To observe ethical considerations, all information provided is treated as confidential by the researcher, and the names of individuals were not released at the analysis and reporting stage.

\section{Consent for publication}

Consent forms were given and signed by all subjects prior to participation.

\section{Competing interests}

The authors declare that they have no competing interests.

\section{Author details}

'Department of Oral and Maxillofacial Radiology, Dental School, Hamadan University of Medical Sciences, Hamadan, Iran. ${ }^{2}$ Department of Biostatistics, School of Public Health and Research Center for Health Sciences, Hamadan University of Medical Sciences, Hamadan, Iran. ${ }^{3}$ Department of Oral and Maxillofacial Radiology, Dental School, Azad University of Medical Sciences, Tehran, Iran.

Received: 16 April 2019 Accepted: 30 December 2019

1.

\section{References}

Afify MM, Zayet MK, Mahmoud NF, Ragab AR (2014) Age estimation from pulp/ tooth area ratio in three mandibular teeth by panoramic radiographs: study of an Egyptian sample. Journal of Forensic Research 5(3):1

Azrak B, Victor A, Willershausen B, Pistorius A, Hörr C, Gleissner C (2007) Usefulness of combining clinical and radiological dental findings for a more accurate noninvasive age estimation. J Forensic Sci 52(1):146-150

Babshet M, Acharya AB, Naikmasur VG (2010) Age estimation in Indians from pulp/tooth area ratio of mandibular canines. Forensic Sci Int 197(1-3):125

Bosmans N, Ann P, Aly M, Willems G (2005) The application of Kvaal's dental age calculation technique on panoramic dental radiographs. Forensic Sci Int 153(2):208-212

Cameriere R, Cunha E, Sassaroli E, Nuzzolese E, Ferrante L (2009) Age estimation by pulp/tooth area ratio in canines: study of a Portuguese sample to test Cameriere's method. Forensic Sci Int 193(3):128-134

Cameriere R, De Luca S, Alemán I, Ferrante L, Cingolani M (2012) Age estimation by pulp/tooth ratio in lower premolars by orthopantomography. Forensic Sci Int 214(1):105-112

Cameriere R, Ferrante L, Belcastro MG, Bonfiglioli B, Rastelli E, Cingolani M (2007) Age estimation by pulp/tooth ratio in canines by peri-apical $X$-rays. J Forensic Sci 52(1):166-170

De Angelis D, Gaudio D, Guercini N, Cipriani F, Gibelli D, Caputi S, Cattaneo C (2015) Age estimation from canine volumes. Radiol Med 120(8):731-736

Farhadian M, Salemi F, Saati S, Nafisi N (2019) Dental age estimation using the pulpto-tooth ratio in canines by neural networks. Imaging Sci Dent 49(1):19-26

Igbigbi P, Nyirenda SK (2006) Age estimation of Malawian adults from dental radiographs. West Afr J Med 24(4):329-333
Indira AP, Shashikala R, Tejavathi N, Santosh HN (2015) Age estimation of adults using dental pulp: a cross-sectional radiographic study. Journal of Advanced Clinical \& Research Insights 2:131-134

Jagannathan N, Neelakantan P, Thiruvengadam C, Ramani P, Premkumar P, Natesan A et al (2011) Age estimation in an Indian population using pulp/ tooth volume ratio of mandibular canines obtained from cone beam computed tomography. J Forensic Odontostomatol 29(1):1-6

Jain RK, Rai B (2009) Age estimation from permanent molar's attrition of Haryana population. Indian J Forensic Odontol 2(2):59-61

Jeon HM, Kim JH, Heo JY, Ok SM, Jeong SH, Ahn YW (2015) Age estimation by radiological measuring pulp chamber of mandibular first molar in Korean adults. Journal of Oral Medicine and Pain 40(4):146-154

Juneja M, Devi YB, Rakesh N, Juneja S (2014) Age estimation using pulp/tooth area ratio in maxillary canines-A digital image analysis. J Forensic Dent Sci 6(3):160-165

Kvaal SI, Kolltveit KM, Thomsen IO, Solheim T (1995) Age estimation of adults from dental radiographs. Forensic Sci Int 74(3):175-185

Landa M, Garamendi P, Botella M, Alemán I (2009) Application of the method of Kvaal et al. to digital orthopantomograms. Int J Legal Med 123(2):123-128

Maret D, Peters O, Dedouit F, Telmon N, Sixou M (2011) Cone-beam computed tomography: a useful tool for dental age estimation? Med Hypotheses 76(5): 700-702

Mathew DG, Rajesh S, Koshi E, Priya LE, Nair AS, Mohan A (2013) Adult forensic age estimation using mandibular first molar radiographs: a novel technique. Journal of forensic dental sciences 5(1):56

Paewinsky E, Pfeiffer H, Brinkmann B (2005) Quantification of secondary dentine formation from orthopantomograms-a contribution to forensic age estimation methods in adults. Int J Legal Med 119(1):27-30

Salemi F, Shokri A, Foroozandeh M, Karami M, Khalili Z (2018) Mandibular lingual concavity: a cross-sectional analysis using cone beam computed tomography. J Clin Diagn Res 12(10):ZC37-ZC41

Saxena S (2011) Age estimation of indian adults from orthopantomographs. Braz Oral Res 25(3):225-229

Singaraju S, Sharada P (2009) Age estimation using pulp/tooth area ratio: a digital image analysis. J Forensic Dent Sci 1:37-41

Star H, Thevissen P, Jacobs R, Fieuws S, Solheim T, Willems G (2011) Human dental age estimation by calculation of pulp-tooth volume ratios yielded on clinically acquired cone beam computed tomography images of monoradicular teeth. J Forensic Sci 56(1):77-82

Wu Y, Niu Z, Yan S, Zhang J, Shi S, Wang T (2016) Age estimation from root diameter and root canal diameter of maxillary central incisors in Chinese Han population using cone-beam computed tomography. Int J Clin Exp Med 9(6):9467-9472

Yang F, Jacobs R, Willems G (2006) Dental age estimation through volume matching of teeth imaged by cone-beam CT. Forensic Sci Int 159(1):78-83

Zaher JF, Fawzy IA, Habib SR, Ali MM (2011) Age estimation from pulp/tooth area ratio in maxillary incisors among Egyptians using dental radiographic images. J Forensic Leg Med 18(2):62-65

\section{Publisher's Note}

Springer Nature remains neutral with regard to jurisdictional claims in published maps and institutional affiliations.

\section{Submit your manuscript to a SpringerOpen ${ }^{\circ}$ journal and benefit from:}

- Convenient online submission

- Rigorous peer review

- Open access: articles freely available online

- High visibility within the field

- Retaining the copyright to your article

Submit your next manuscript at $>$ springeropen.com 